http://jmscr.igmpublication.org/home/ ISSN (e)-2347-176x ISSN (p) 2455-0450 crossref DOI: https://dx.doi.org/10.18535/jmscr/v7i9.13

\title{
A Study of Antepartum Hemorrhage and Its Maternal and Perinatal Outcome at Tertiary Care Hospital in Western Rajasthan
}

\author{
Authors \\ Mangal Chand Yadav*, Kalpana Mehta, Vimla Choudhary \\ Department of Obstetrics and Gynecology, Dr S N Medical College, Jodhpur, Rajasthan \\ *Corresponding Author \\ Mangal Chand Yadav \\ Dr S N Medical College, Department of Obstetrics and Gynecology, Jodhpur, Rajasthan, India
}

\begin{abstract}
Background: Antepartum hemorrhage is an obstetric emergency contributing to a significant amount of perinatal \& maternal morbidity and mortality. The main causes of APH are placenta previa, abruptio placentae, indeterminate cause or local causes of genital tract. APH complications can be fetal as well as maternal. The maternal complications are malpresentation, premature labor, postpartum hemorrhage, sepsis, shock and retained placenta. Various fetal complications are prematurity, low birth weight, intrauterine death, congenital malformation and birth asphyxia.

Objective: To study maternal and perinatal outcome in patients of APH at a tertiary care referral hospital in Western Rajasthan.

Material and Methods: This was a retrospective observational study conducted over a period of one year. A total of 112 cases of APH were studied. The diagnosis of all cases was made on the basis of history, clinical examination and ultrasonography. All the cases of hemorrhage were grouped as: Placenta Previa, Abruptio Placenta or other causes.

Results: Out of 8623 deliveries, 112 had APH, incidence being 1.29\%. Maximum number of cases about 86(76.8\%) were of placenta previa followed by abruptio placentae in 23 cases (20.5\%) and the least was unclassified hemorrhage $3(2.7 \%)$. The incidence of APH was highest $43.8 \%$ in the age group 25-29 years. Anemia was the most common complication (51.7\%) in APH patients. Neonatal jaundice was the most common complication (26.8\%) amongst the neonate of $A P H$.

Conclusion: High incidences of APH are associated with iron deficiency anemia and lack of awareness in India. Maternal and perinatal morbidity and mortality could be prevented by early regular antenatal care, improved nutritional status, better antenatal services, increased awareness, and timely caesarean section.

Keywords: Abruptio Placenta, Anemia, Antepartum hemorrhage, Placenta Previa.
\end{abstract}

\section{Introduction}

Antepartum hemorrhage (APH) is an obstetric emergency contributing to a significant amount of perinatal \& maternal morbidity and mortality. It is defined as bleeding from the vagina after 24 weeks of gestation. It occurs in $2-5 \%$ of pregnancies and is an important cause of fetal and maternal death. Thirty percent of maternal deaths are caused by antepartum hemorrhage of which $50 \%$ are associated with avoidable factors ${ }^{1}$. In India, the prevalence of antepartum hemorrhage is reported to be $18.8 \%{ }^{2}$.

The main causes of APH are placenta previa, abruptio placentae, indeterminate cause or local causes of genital tract. Placenta previa exists when the placenta is implanted wholly or in part into the 
lower segment of the uterus. An abruption placenta is the condition whenever bleeding occurs due to premature separation of a normally sited placenta. Other causes are cervical polyp, cervical carcinoma local lesions of vagina and cervix. Systemic diseases like leukemia \& bleeding disorders are rare causes of APH. Placenta previa and Abruptio placentae account for almost half cases of $\mathrm{APH}^{3}$.

However, during APH, complications can be fetal as well as maternal. The maternal complications are malpresentation, premature labor, postpartum hemorrhage (PPH), sepsis, shock and retained placenta $^{4}$. Various fetal complications are prematurity, low birth weight, intrauterine death, congenital malformation and birth asphyxia ${ }^{5}$.

In developed countries, maternal mortality due to antepartum hemorrhage has been reduced significantly due to better obstetrical facility and care. But in developing countries like India maternal and perinatal mortality is still very high due to associated problems like anemia, difficulties in transport in cases of emergency and restricted medical facilities ${ }^{6}$. So we planned to study maternal and perinatal outcome in patients of APH at a tertiary care referral hospital in Western Rajasthan.

\section{Material and Methods}

Study Population: This was a retrospective observational study conducted in Dr S N Medical College, Jodhpur, Rajasthan over a period of one year from June 2017 to May 2018. There were a total of 8623 deliveries during this period and 112 women had APH. Data were collected from the records present in Labor ward and Medical record section.

All patients with bleeding per vaginum after 28 weeks of gestation but before birth of the fetus were included in the study. Cases with bleeding before 28 weeks and after delivery of the baby were excluded.

\section{Methodology}

The diagnosis of all cases was made on the basis of history, clinical examination and ultrasonography. All the cases of hemorrhage were grouped as - Placenta Previa (PP), Abruptio Placenta (AP) or other causes. Statistical analysis was done by using SPSS software version 21 . Institutional ethical committee clearance had been taken for this study.

\section{Results}

Out of 8623 deliveries, 112 had APH, incidence being $1.29 \%$. Maximum number of cases about 86 (76.8\%) were of placenta previa followed by abruptio placentae in 23 cases $(20.5 \%)$ and the least was unclassified hemorrhage $3(2.7 \%)$.

The incidence of APH was highest $43.8 \%$ in the age group $25-29$ years followed by $24.1 \%$ in the age group of 30-34 years and the least was $10.71 \%$ in the age group more than 35 years. Majority of the patients 73(64.88\%) were unbooked while $39(35.12 \%)$ were booked. APH is more common in multipara $83.92 \%$ than in nullipara $16.07 \%$.

Maximum patients of APH delivered by caesarean section $(77.7 \%)$ as compared to vaginal delivery (22.3\%). 78 patients of placenta previa group underwent caesarean section whereas 9 patients from abruptio placentae underwent caesarean section.

Anemia was the most common complication (51.7\%) in APH patients followed by postpartum hemorrhage (21.4\%). One patient had renal failure in placenta previa. 6 patients of placenta previa had sepsis. 3 patients of placenta previa had scar dehiscence. 3 patient of abruptio placenta and 5 patient of placenta previa underwent caesarean hysterectomy.

Neonatal jaundice was the most common complication (26.8\%) amongst the neonate of APH followed by prematurity (22.3\%), birth asphyxia $(2.67 \%)$ and hyaline membrane disease were $(0.9 \%)$. Out of 112 cases $69(61.7 \%)$ babies were low birth weight. Among that 53(47.3\%) were placenta previa and 15(13.39\%) were abruptio placentae. There were 18 still births and early neonatal death in the case of placenta previa. 
Table 1 Distribution of patients according to age group

\begin{tabular}{|l|c|c|c|c|c|}
\hline Type of APH & $\mathbf{2 0 - 2 4}$ years & $\mathbf{2 5 - 2 9}$ years & $\mathbf{3 0 - 3 4}$ years & >35 years & Total \\
\hline Placenta previa & 20 & 37 & 19 & 10 & 86 \\
\hline Abrubtio placentae & 04 & 10 & 07 & 02 & 23 \\
\hline Unclassified Hemorrhage & 0 & 02 & 01 & 0 & 03 \\
\hline Total & 24 & 49 & 27 & 12 & 112 \\
\hline
\end{tabular}

Table 2 Distribution of patients according to cause of APH

\begin{tabular}{|l|c|c|}
\hline Type of APH & Frequency & Percentage \\
\hline Placenta Previa & 86 & 76.8 \\
\hline Abrubtio placentae & 23 & 20.5 \\
\hline Unclassified Hemorrhage & 03 & 2.7 \\
\hline Total & 112 & 100 \\
\hline
\end{tabular}

Table 3 Mode of delivery

\begin{tabular}{|l|c|c|c|}
\hline Type of APH & Caesarian section & Vaginal delivery & Total \\
\hline Placenta Previa & $78(90.7 \%)$ & $08(9.3)$ & 86 \\
\hline Abrubtio placentae & $09(39.1)$ & $14(60.9)$ & 23 \\
\hline Unclassified Hemorrhage & $0(0 \%)$ & $03(100 \%)$ & 03 \\
\hline Total & $87(77.7 \%)$ & $25(22.3 \%)$ & 112 \\
\hline
\end{tabular}

Table 4 Distribution of patients according to parity

\begin{tabular}{|l|c|c|c|c|c|c|c|}
\hline Type of APH & P 0 \% & P 1\% & P2 \% & P 3\% & P 4 \% & P5 \% & Total \\
\hline Placenta Previa & 12 & 32 & 30 & 9 & 1 & 2 & 86 \\
\hline Abrubtio placentae & 6 & 8 & 5 & 3 & 0 & 1 & 23 \\
\hline Unclassified Hemorrhage & 0 & 2 & 0 & 0 & 1 & 0 & 03 \\
\hline Total & 18 & 42 & 35 & 12 & 02 & 03 & 112 \\
\hline
\end{tabular}

Table 5 Maternal outcome

\begin{tabular}{|l|c|c|c|c|}
\hline Maternal outcome & $\begin{array}{c}\text { Placenta } \\
\text { Previa }\end{array}$ & $\begin{array}{c}\text { Abrubtio } \\
\text { Placentae }\end{array}$ & $\begin{array}{c}\text { Unclassified } \\
\text { Hemorrhage }\end{array}$ & Total \\
\hline Uneventful & 5 & 2 & 2 & 09 \\
\hline Anemia & 45 & 13 & 0 & 58 \\
\hline Caesarian section hysterectomy & 05 & 3 & 0 & 08 \\
\hline PPH & 19 & 4 & 1 & 24 \\
\hline Renal failure & 01 & 0 & 0 & 01 \\
\hline Scar dehiscence & 03 & 1 & 0 & 04 \\
\hline Sepsis & 06 & 0 & 0 & 06 \\
\hline UTI & 2 & 0 & 0 & 02 \\
\hline Total & 86 & 23 & 03 & 112 \\
\hline
\end{tabular}

Table 6 Perinatal outcome

\begin{tabular}{|l|c|c|c|c|}
\hline Morbidity & $\begin{array}{c}\text { Placenta } \\
\text { Previa }\end{array}$ & $\begin{array}{c}\text { Abrubtio } \\
\text { placentae }\end{array}$ & $\begin{array}{c}\text { Unclassified } \\
\text { Hemorrhage }\end{array}$ & Total \\
\hline Normal & 33 & 18 & 02 & 53 \\
\hline Birth asphyxia & 3 & 0 & 0 & 03 \\
\hline Hyaline membrane disease & 1 & 0 & 0 & 01 \\
\hline Neonatal jaundice & 30 & 0 & 0 & 30 \\
\hline Prematurity & 19 & 05 & 1 & 25 \\
\hline Total & 86 & 23 & 03 & 112 \\
\hline Fetal weight & & & & \\
\hline Low birth weight & 53 & 15 & 1 & 69 \\
\hline Normal & 33 & 08 & 2 & 43 \\
\hline Total & 86 & 23 & 03 & 112 \\
\hline Fetal Mortality & & & & \\
\hline Normal & 60 & 20 & 3 & 83 \\
\hline Birth Asphyxia & 05 & 01 & 0 & 06 \\
\hline Still birth and early neonatal death & 18 & 02 & 0 & 20 \\
\hline RDS & 03 & 0 & 0 & 03 \\
\hline Total & 86 & 23 & 03 & 112 \\
\hline
\end{tabular}




\section{Discussion}

Obstetric hemorrhage remains one of the major causes of maternal death in developing countries and is the cause of up to $50 \%$ of the estimated 500 000 maternal deaths that occur globally each year ${ }^{7}$. Obstetric hemorrhage encompasses both antepartum and postpartum bleeding. (R COG) Antepartum hemorrhage is an important cause of perinatal mortality and maternal morbidity in pregnant women with placenta previa in the world. It is found that there is a strong relationship between APH and later development of intrapartum bleeding necessitating cesarean delivery ${ }^{8}$.

In this study the incidence of APH was found to be $1.29 \%$ which is concordant with the study conducted by P Rajini et $\mathrm{al}^{9}(1.2 \%)$ while there are studies who reported higher percentage of APH i.e Sunil K et al ${ }^{10}(2.9 \%)$, Singhal et $\mathrm{al}^{6}(3.01 \%)$ and Sheikh et $\mathrm{al}^{11}(5.4 \%)$ in their studies. However Ratnam SS et al ${ }^{12}$ reported $0.6 \%$ in their study.

In this study majority of the cases of APH were due to placenta previa (76.8\%) followed by abruptio $(20.5 \%)$ which is similar to studies done by Maurya et $\mathrm{al}^{13}$, Adekanle et $\mathrm{al}^{14}$.

In this study the incidence of APH was highest $43.8 \%$ in the age group $25-29$ years followed by $24.1 \%$ in the age group of $30-34$ years which is concordant with the study conducted by Adekanle et $\mathrm{al}^{14}$ in which $40 \%$ APH patients were between 25-29 years while Priyanka et al ${ }^{15}$ revealed that $61 \%$ of APH cases were aged $26-30$ years. In another study conducted by Das et al. ${ }^{16}$, Abbasi et $\mathrm{al}^{17}$. The mean age of patients presented with APH was 30 years.

In this study $64.8 \%$ cases of APH were unbooked and reported in emergency with bleeding per vaginum or labour pains. This was similar to previous studies done by Maurya et $\mathrm{al}^{13}$ which reports $62 \%$ unbooked cases and same result was seen with study by Pandey et $\mathrm{al}^{18}$, Adekanle et $\mathrm{al}^{14}$.

In this study the incidence of caesarean section in present study is $77.7 \%$. The incidence of caesarean section in placenta previa group is
90.7\% similar to the study done by Khouri JA \& Sultan $\mathrm{MG}^{19}$. The incidence of caesarean in the abruption placentae group in this study is $39.1 \%$ while that reported by Hurd et $\mathrm{al}^{20}$ from the UK and the study reported by Rochelle et $\mathrm{al}^{21}$ at Washington State were $50 \%$ \& $37.9 \%$ respectively.

In this study we found that incidence of APH is more in multigravida (84\%) than in primigravida $(16 \%)$. Other studies such as Gillium et al. ${ }^{22}$ and Clark et al. ${ }^{23}$ have also reported high incidence of APH in multipara which was about 5-8 times higher than primigravida thus confirming the role of endometrial damage caused by repeated childbirth, a risk factor for uteroplacental bleeding in pregnancy.

In this study anemia was the most common complication $(51.7 \%)$ in APH patients followed by postpartum hemorrhage $(21.4 \%)$ which is similar to the earlier studies from Assam ${ }^{24}$. Maternal anemia is significantly associated with age, religion, education and socioeconomic status $^{25}$.

In this study neonatal jaundice was the most common complication (26.8\%) amongst the neonate of APH followed by prematurity (22.3\%). In this study out of $112(61.6 \%)$ babies was low birth weight. Among that 53(47.3\%) were placenta previa and $15(13.39 \%)$ were abruptio placentae which is similar to studies conducted by Khosla et $\mathrm{al}^{26}$ while other authors such as Arora et $\mathrm{al}^{27}$ and Sneha et $\mathrm{al}^{28}$ reported $77 \%$ and $40 \%$ low birth weight respectively. Babies having low birth weight are associated with maximum perinatal death. Perinatal mortality was $35 \%$ in the present study while Arora et al. $^{27}$ and Khosla et al. ${ }^{26}$ reported very higher perinatal mortality $61.5 \%$ and $53.5 \%$ respectively. However Robbins et al. [22] reported $18.44 \%$. This difference may be due to advanced neonatal intensive care facility in the present institute.

\section{Conclusion}

Our findings suggest that high incidences of APH are associated with iron deficiency anemia and 
lack of awareness in India. We feel that maternal and perinatal morbidity and mortality could be prevented by early registration, regular antenatal care, improved nutritional status, better antenatal services, increased awareness, improved transportation and timely caesarean section can help to address the complications associated with APH. Good facilities for caesarean section, availability of blood banks and good NICU set up and multidisciplinary approach can improve maternal and perinatal outcome of APH.

\section{References}

1. David A Miller. Treatment of Antepartum Hemorrhage. Women's and children's Hospital, Department of obstetrics and Gynaecology, Los Angeles, USA.

2. Sharma S, Sidhu H, Kaur S. Analytical study of intrauterine fetal death cases and associated maternal conditions. Int J Appl Basic Med Res 2016;6:11-3

3. Nicholas Ngeh, Amarnath Bhide. Antepartum haemorrhage. Current obstetrics \& Gynaecology 2006;16(2):7983

4. Kedar K, Uikey P, Pawar A, Choudhary A. Maternal and fetal outcome in antepartum haemorrhage: a study at tertiary care hospital. Int J Reprod Contracept Obstet Gynecol. 2016;5:1386-93.

5. Cunningham $\mathrm{F}$, Leveno $\mathrm{K}$, Bloom $\mathrm{S}$, Hauth J, Gilstrap L, Rouse D et al. Obstetrical hemorrhage. Williams obstetrics. 23. New York: McGraw Hill Professionals; 2009:2-3.

6. Singhal S, Nymphaea, Nanda S. Maternal and perinatal outcome in antepartum haemorrhage: A study at a tertiary care referral institute. The Internet J Gynaecol Obstet. 2008;9(2):5580.

7. Khan KS, Wojdyla D, Say L, Gülmezoglu AM, Van Look PF. WHO analysis of causes of maternal death: a systematic review. Lancet 2006;367:1066-74
8. Sinha P. \& Kuruba N. Ante-partum hemorrhage: an update. J Obstet Gynaecol. 2008;28:377-81

9. Rajini P, Devi V A, Singh A, Girishma P. Maternal and perinatal outcomes in cases of antepartum hemorrhage. IOSR Journal of Dental and Medical Sciences. 2016;15(6):9-11

10. Samal SK, Rathod S, Rani R, Ghose S. Maternal and perinatal outcomes in cases of antepartum hemorrhage: a 3-year observational study in a tertiary care hospital. Int J Reprod Contracept Obstet Gynecol 2017;6:1025-9

11. Sheikh F, Khokhar S, Sirichand P, Shaikh R. A study of antepartum hemorrhage: Maternal and perinatal outcome. Medical Channel. 2010;16(2):268-71

12. Ratnam SS, Bhaskar Rao K, Arul Kumaran. APH. Obstetrics and Gynecology for post graduates. (1st edn), Orient Longman Ltd, Chennai, India 1994;1:77-93

13. Maurya A, Arya S. Study of Antepartum Haemorrhage and Its Maternal and Perinatal Outcome. Int J Sci Res Publ. 2014.

14. Adekanle DA, Adeyemi AS, Fadero FF. Antepartum haemorrhage and pregnancy outcome in Lautech teaching Hospital, southwestern Nigeria. J Med Sci. 2011:1243-7

15. Tyagi P, Yadav N, Sinha P, Gupta U. Study of antepartum haemorrhage and its maternal and perinatal outcome. Int $\mathrm{J}$ Reprod Contracept Obstet Gynecol 2016;5:3972-7

16. Das B Antepartum haemorrhage in three decades. J Obstet Gynaecol India 1978;25:636-7

17. Abbasi RM, Rizwan N, Farooq S Fetomaternal outcome among abruption placenta cases at a University hospital of Sindh. J Liaquat Uni Med Health Sci 2008;7(2):106-9 
18. Pandey VP, Pandey M. Study of Antepartum Haemorrhage and its Maternal and Perinatal Outcome. 2016. Available from: http: imsear.li.mahidol.ac.th/handle/123456789/ 175784

19. Khouri JA, Sultan MG Previous Caesarean section and the rising incidence of Placenta previa and Placenta accrete. J Obstet Gynecol 1994;14(1):14-6

20. Hurd WW, Miodovnik M, Hertzberg V, Lavin JP Selective management of Abruptio placenta: A prospective study. Obstet Gynecol 1983;61(4): 467-533

21. Lydon-Rochelle M, Holt VL, Easterling TR, Martin DP First birth caesarean and placental abruption or previa at second birth. J Obstet Gynecol 2001;97(5 Pt 1):765-9

22. Gilliam M, Rosenberg D, Davis F The likelihood of placenta previa with greater number of cesarean deliveries and higher parity. Obstet Gynecol 2002;99(6):976-80

23. Clark SL, Koonings PP, Phelan JP Placenta previa/ Accreta and prior Caesarean section. Obstet Gynecol 1985;66(1):89-92

24. Malakar M, Malakar M. High prevalence of anemia in pregnant women of Lakhimpur District of Assam. Indian Journal of Basic and Applied Medical Research 2014;3:314-21

25. Biswas M, Baruah R. Maternal anemia associated with socio-demographic factors among pregnant women of Boko-Bongaon Block Kamrup, Assam. Indian Journal of Basic and Applied Medical Research 2014;3:712-21

26. Khosla A, Dahiya V, Sangwan K, Rathore $S$ Perinatal outcome in Antepartum haemorrhage. J Obstet Gynae India 1989;9:71-3

27. Arora R, Devi U, Majumdar R Perinatal morbidity and mortality in Antepartum haemorrhage. J Obstet Gynecol India 2001;51(30):102-4

28. Wasnik SK, Naiknaware SV Antepartum Hemorrhage: Causes \& Its Effects on Mother and Child: An Evaluation. Obstet Gynecol Int J 2015;3(1):00072 DOI: 10.15406/ogij.2015.03.00072

29. Robbins PG, Gorbach AG Jr, Reid DE Neurologic abnormalities at one year in infants delivered after late pregnancy haemorrhage. Obstet Gynecol 1967;29(3):358-61 